\title{
Study on the Shape Memory Polyamides. Synthesis and Thermomechanical Properties of Polycaprolactone- Polyamide Block Copolymer
}

\author{
Ha Yung Lee, Han Mo Jeong, Jeong Sam LeE,* and Byung Kyu Kim* \\ Department of Chemistry, University of Ulsan, Ulsan 680.749 , Republic of Korea \\ * Department of Polymer Science and Engineering, Pusan National University,
}

Pusan 609-735, Republic of Korea

(Received March 18, 1999)

\begin{abstract}
Poly(caprolactone)(PCL)-polyamide multiblock copolymers were synthesized by the linear chain extension of PCL diol and diamine-terminated polyamide oligomer with hexamethylene diisocyanate in dimethylformamide. The thermal and mechanical properties of these block copolymers were examined and compared with the results in our previous papers about thermoplastic polyurethane elastomers (TPEs). PCL-polyamide block copolymers showed enhanced microphase separation and lower degree of fatigue by repeated deformation in shape memory behavior, and had higher rubbery plateau modulus, compared with TPEs.

KEY WORDS Polyamide / Polycaprolactone/Multiblock Copolymer/Thermal Properties / Mechanical Properties / Shape Memory /
\end{abstract}

Thermal-responsive shape memory polymers basically consist of the fixed structure for memorizing original shape and the thermally reversible phase for maintaining transient shape. ${ }^{1,2}$ Crystal, glassy state, entanglement, or crosslinking can be used as a fixed structure. Thermally reversible phase is generally designed to have a large drop in elastic modulus above shape recovery temperature $\left(T_{\mathrm{s}}\right)$, i.e., glass transition temperature $\left(T_{\mathrm{g}}\right)$ or melting temperature $\left(T_{\mathrm{m}}\right){ }^{3-5}$

In our previous papers, ${ }^{6,7}$ we reported the shape memory behaviors of thermoplastic polyurethane elastomers (TPEs) from crystalline polycaprolactone (PCL) soft segment and 4,4'-methylenediphenyl diisocyanate (MDI)/1,4-butanediol (BD) based hard segment. Rubber elasticity was indicated at the temperature range between the melting temperature of soft segment $\left(T_{\mathrm{ms}}\right)$ and hard segment $\left(T_{\mathrm{mh}}\right)$ because of the free molecular motion of soft segment and fixed structure of crystalline hard segment. When they were deformed at the temperature range between $T_{\mathrm{ms}}$ and $T_{\mathrm{mh}}$, and subsequently cooled below $T_{\text {ms }}$ under constant strain, the deformed shape is fixed because the molecular motion of PCL segment is restricted when crystallized below $T_{\mathrm{ms}}$. If they were reheated to the temperature range between $T_{\mathrm{ms}}$ and $T_{\mathrm{mh}}$, the original shape is recovered again. The driving force of shape recovery is the elastic force generated during the deformation. These polyurethanes are thermoplastic because they can flow above $T_{\mathrm{mh}}$.

For TPEs, the crystallization of soft and hard segments and the role of hard segment as physical crosslink or fixed phase are enhanced when the soft-hard phase mixing is reduced. ${ }^{8,9}$ And lower residual strain after shape recovery was observed in our previous study on the shape memory behaviors when the soft-hard phase mixing was reduced or rubbery plateau modulus was enhanced. ${ }^{7}$

We observed the segmental interaction between polyester or polyether soft segment and MDI/BD based hard segment and the consequent phase mixing was re- duced as hard segment was replaced by polyamide segment. ${ }^{10,11}$ So, in this study we synthesized PCLpolyamide multiblock copolymers, and their thermal and mechanical properties, including shape memory behavior, were observed and compared with those of TPEs.

\section{EXPERIMENTAL}

\section{Materials}

$N, N$-Dimethylformamide (DMF, Aldrich) was used after dehydration with $4 \AA$ molecular sieve for more than a week. $\mathrm{LiCl}$ (Junsei) was dried at $150^{\circ} \mathrm{C}$ for $3 \mathrm{~h}$ before use. PCL diol having the number average molecular weight $\left(M_{n}\right) 2000$ (Aldrich) and 4000 (Daicel) were dried at $100^{\circ} \mathrm{C}$ under $10 \mathrm{mmHg}$ for more than $3 \mathrm{~h}$. Hexamethylene diisocyanate (HDI, Aldrich), adipic acid (AA, Aldrich), hexamethylene diamine (HA, Aldrich), $\varepsilon$-caprolactam (CA, Aldrich), phenol (Aldrich), $m$-cresol (Aldrich), chloroform (Aldrich), ethanol (James Burrough), dibutyltin dilaurate (Aldrich), formic acid (96\%, Aldrich) were used as received.

A thermoplastic polyurethane elastomer, 4TPE73 (Run No, 4-70 in our previous paper ${ }^{6}$ ), was synthesized from PCLdiol $\left(M_{n}=4000\right)$, MDI, and BD. The content of PCL segment in 4TPE73 was $70 \mathrm{wt} \%$, and the detailed synthetic method was described in our previous paper. ${ }^{6}$

\section{Synthesis and Characterization of Polyamide Oligomer}

The diamine-terminated nylon $6 / 6,6$ copolyamide oligomer (CPA) 1, having the $M_{n}$ shown in Table I were synthesized by the melt polycondensation reaction of $\mathrm{CA}$, AA, and HA. ${ }^{10,11}$ An excess of HA over AA was used to obtain CPA with terminal amine groups and the molecular weight was controlled by a stoichiometric imbalance of reactants, i.e., by varying the AA/HA feed mole ratio at fixed $\mathrm{CA} / \mathrm{AA}$ feed mole ratio (Table I). $\mathrm{CA}, \mathrm{AA}$, and HA were completely melted at $200^{\circ} \mathrm{C}$ for 
Table I. Characteristics of polyamide oligomers

\begin{tabular}{|c|c|c|c|c|c|}
\hline \multirow{2}{*}{$\begin{array}{l}\text { Designa- } \\
\text { tion }\end{array}$} & \multirow{2}{*}{$\begin{array}{l}\text { Feed mole ratio } \\
\text { of } \mathrm{CA} / \mathrm{AA} / \mathrm{HA}\end{array}$} & \multicolumn{2}{|c|}{$M_{n}$} & \multirow{2}{*}{$\frac{T_{\mathrm{m}}}{{ }^{\circ} \mathrm{C}}$} & \multirow{2}{*}{$\begin{array}{c}\Delta H_{\mathrm{m}} \\
\text { at } T_{\mathrm{m}}\end{array}$} \\
\hline & & NMR & Titration & & \\
\hline CPAI & $2.00 / 1.00 / 2.60$ & 1180 & 1320 & 177 & 81 \\
\hline CPA2 & $2.00 / 1.00 / 1.49$ & 2150 & 2500 & 168 & 53 \\
\hline CPA3 & $2.00 / 1.00 / 1.30$ & - & 3760 & 174 & 55 \\
\hline HPA I & $2.00 /-/ 0.29$ & - & 1340 & 181 & 111 \\
\hline
\end{tabular}

$45 \mathrm{~min}$ in the reaction vessel and reacted at $220^{\circ} \mathrm{C}$ for $2 \mathrm{~h}$ under $\mathrm{N}_{2}$ atmosphere with stirring. The solid product was crushed mechanically after cooling to room temperature, dissolved in hot ethanol to $17 \%(\mathrm{w} / \mathrm{w})$ solution, and precipitated into ten times volume of water. The precipitate was filtered and dried under vacuum at $45^{\circ} \mathrm{C}$ for $48 \mathrm{~h}$. This purification process was repeated three times. The diamine-terminated nylon 6 homopolyamide oligomer (HPA) was similarly synthesized in the absence of AA (Table I).

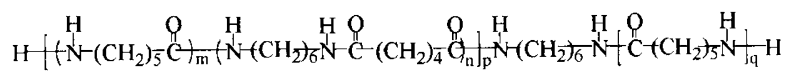

\section{1}

$M_{n}$ of the polyamide oligomer was determined by NMR and titration measurements (Table I). In NMR method the peak intensity of methylene protons adjacent to unreacted terminal amine group at $3.5 \mathrm{ppm}$ was compared with that of methylene protons adjacent to reacted amine group at $3.8 \mathrm{ppm}$. In a typical titration procedure, $0.1 \mathrm{~g}$ of polyamide oligomer was dissolved with $50 \mathrm{~mL}$ of phenol and $20 \mathrm{~mL}$ of chloroform, and the terminal amine group was titrated with $0.01 \mathrm{M} \mathrm{HClO}_{4}$ solution in ethanol.

\section{Synthesis of PCL-Polyamide Block Copolymer}

PCL-polyamide multiblock copolymers were synthesized by the linear chain extension of PCL diol and diamine-terminated polyamide oligomer with HDI in DMF (Figure 1). That is, PCL diol was reacted with HDI at $60^{\circ} \mathrm{C}$ for $30 \mathrm{~min}$ and another $2 \mathrm{~h}$ at $80^{\circ} \mathrm{C}$ in the presence of dibutyltin dilaurate $(0.03 \mathrm{wt} \%$ on solid base) as a catalyst. DMF was added to the reactor occasionally when the viscosity of the reaction mixture became too high. After cooling to room temperature a $20 \%(\mathrm{w} / \mathrm{v})$ solution of polyamide oligomer in LiCl-DMF $(10 \%$ $(\mathrm{w} / \mathrm{v}))$, being divided into three parts, was added into the reactor successively. After feeding, the reaction mixture was agitated for $30 \mathrm{~min}$. Formic acid $(0.1 \mathrm{wt} \%$ on solid base) used to inhibit gelation was added into the reactor before the feeding of polyamide oligomer.

Intrinsic viscosity, $[\eta]$ and the compositions of PCL-polyamide block copolymers are shown in Table II.

The sample designation code in Table II indicates the molecular weight and the content of PCL block, and the kind of polyamide block in PCL-polyamide block copolymer. For example, 4P1HN73 indicates that this PCL-polyamide block copolymer was synthesized with PCL diol whose $M_{n}$ is 4000 and HPAl (Table I), and the content of PCL segment is about $70 \mathrm{wt} \%$.

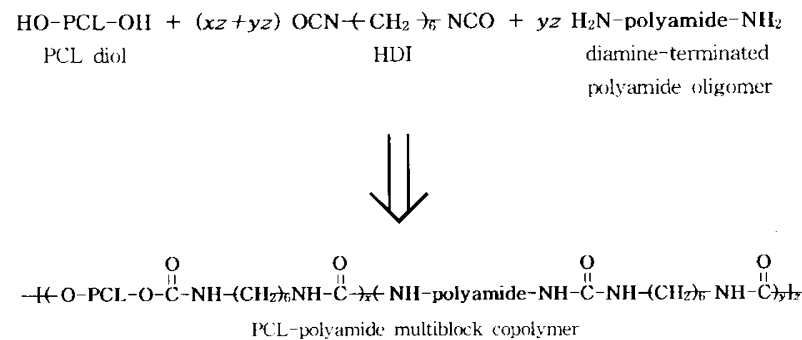

Figure 1. Reaction scheme of PCL diol, diamine-terminated polyamide oligomer, and HDI to give PCL-polyamide multiblock copolymer.

\section{Characterization}

PCL-polyamide block copolymers were characterized after $\mathrm{LiCl}$ was removed. That is, film was made by spreading polymerized solution on a polyethylene plate and evaporating DMF in a convection oven at $80^{\circ} \mathrm{C}$ for $5 \mathrm{~h}$. This film was further dried for $24 \mathrm{~h}$ in a vacuum oven at $80^{\circ} \mathrm{C}$ and immersed in distilled water for 3 days to remove $\mathrm{LiCl}$, and dried again in a vacuum oven at $80^{\circ} \mathrm{C}$ for $12 \mathrm{~h}$. This film was redissolved in $m$-cresol to give $10 \%(\mathrm{w} / \mathrm{w})$ solution and final cast film was obtained on a polyethylene plate by evaporating $m$-cresol in a vacuum oven for $24 \mathrm{~h}$ at $90^{\circ} \mathrm{C}$.

The viscosity of PCL-polyamide block copolymer solution in $m$-cresol was measured with Ostwald viscometer at $25^{\circ} \mathrm{C}$.

${ }^{1} \mathrm{H}$ NMR spectra were obtained in $\mathrm{CF}_{3} \mathrm{COOD}$ on a Varian Unity Plus 300.

Differential scanning calorimetry (DSC) was carried out with TA Instruments DSC-2910 at a heating rate and a cooling rate of $10^{\circ} \mathrm{Cmin}^{-1}$. All runs were carried out with a sample of $c a .5 \mathrm{mg}$. The DSC thermograms in Figure 2 and the thermal properties in Table III were determined as foliows. After melting for $3 \mathrm{~min}$ at $20^{\circ} \mathrm{C}$ above the melting temperature $\left(T_{\mathrm{mh}}\right)$ of polyamide segment in DSC device, the crystallization temperature $\left(T_{\mathrm{mch}}\right)$ and the heat of crystallization $\left(\Delta H_{\mathrm{mch}}\right)$ of polyamide segment, and the crystallization temperature $\left(T_{\text {mcs }}\right)$ and the heat of crystallization $\left(\Delta H_{\mathrm{mcs}}\right)$ of PCL segment were measured on cooling scan to $-140{ }^{\circ} \mathrm{C}$. On the subsequent heating scan after staying $1 \mathrm{~min}$ at $-140^{\circ} \mathrm{C}$, the glass transition temperature $\left(T_{\mathrm{gs}}\right)$, the melting temperature $\left(T_{\mathrm{ms}}\right)$, and the heat of fusion $\left(\Delta H_{\mathrm{ms}}\right)$ of PCL segment, the crystallization temperature of polyamide segment $\left(T_{\mathrm{mhh}}\right)$, and $T_{\mathrm{mh}}$ and the heat of fusion $\left(\Delta H_{\mathrm{mh}}\right)$ of polyamide segment were measured. The thermal properties in Table I were measured on heating the scan from $-5^{\circ} \mathrm{C}$ to $220^{\circ} \mathrm{C}$.

Dynamic mechanical properties of cast film were determined using a dynamic mechanical thermal analyzer(Rheometric Scientific, PL-DMTA MK III) at $1 \mathrm{~Hz}$ and at a heating rate of $3 \mathrm{Cmin}^{-1}$.

Tensile tests were done at a strain rate of $500 \mathrm{~mm}$ $\min ^{-1}$ using a tensile tester (Tinius Olsen Series 1000), attaching a constant temperature heating chamber. Microtensile specimen for test has the dimensions of $40 \mathrm{~mm}$ length, $10 \mathrm{~mm}$ width, and $0.2 \mathrm{~mm}$ thickness. 
Table II. Characteristics of PCL-polyamide block copolymers

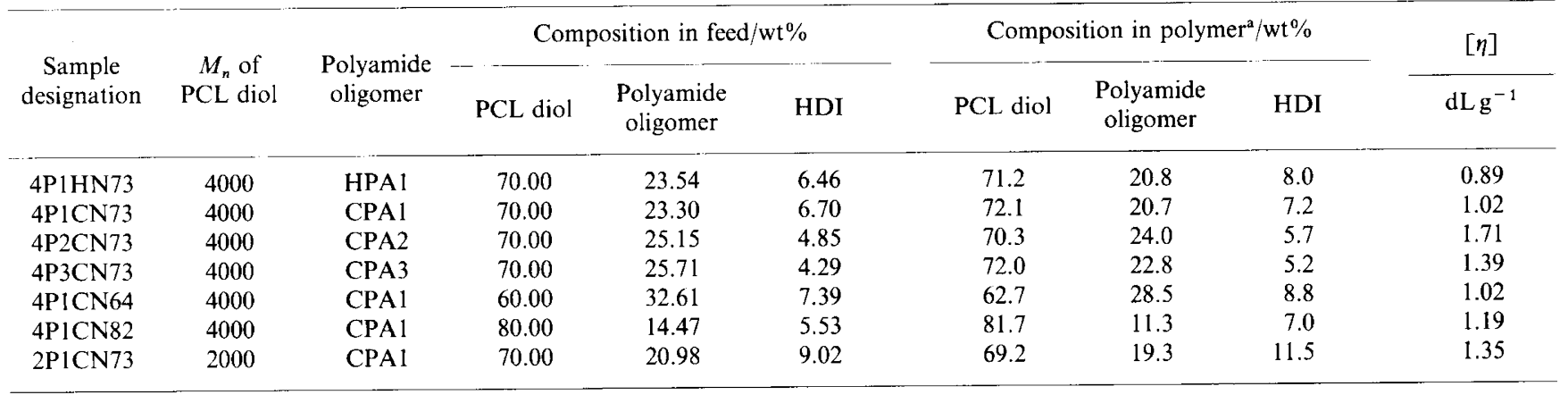

${ }^{a}$ Determined by ${ }^{1} \mathrm{H}$ NMR analysis.

\section{RESULTS AND DISCUSSION}

\section{Thermal Properties}

DSC thermograms of some typical PCL-polyamide block copolymers are shown in Figure 2. All the thermograms obtained on cooling from the melt state show a sharp exothermic crystallization peak $\left(T_{\text {mcs }}\right)$ of PCL segment, and that of 4P3CN73 exceptionally has the crystallization peak $\left(T_{\mathrm{mch}}\right)$ of polyamide segment also. This result suggests that the relatively longer polyamide segment in $4 \mathrm{P} 3 \mathrm{CN} 73$ can relatively easily crystallize on cooling scan. The thermograms of 4P1CN73 and 4P2CN73, obtained on subsequent heating scan, show $T_{\mathrm{gs}}, T_{\mathrm{ms}}$, the small crystallization peak of polyamide segment $\left(T_{\mathrm{mhh}}\right)$, and $T_{\mathrm{mh}}$. However, 4P3CN73, whose polyamide segment was crystallized on cooling scan, does not have the peak of $T_{\text {mhb }}$. The $T_{\text {mh }}$ placed just above $T_{\mathrm{ms}}$ suggests the possibility that the glass transition of polyamide segment is masked by the melting peak of PCL segment, because the crystallization on heating can occur above the glass transition temperature. The thermal properties measured by DSC are summarized in Table III. All the $T_{\mathrm{gs}}$ shown in Table III lies in the temperature range $-63^{\circ} \mathrm{C}--56^{\circ} \mathrm{C}$. In TPEs, $T_{\mathrm{g}}$ of soft segment generally increases as some of hard segment is dissolved into soft segment domain due to phase mixing. ${ }^{12,13}$ As the $T_{\mathrm{g}}$ of pure PCL is about $-60^{\circ} \mathrm{C},{ }^{14}$ the results of $T_{\mathrm{gs}}$ in Table III suggest that the dissolution of polyamide segment into PCL domain is not so much. Compared with other PCL-polyamide block copolymers, 4P3CN73 and 4P1CN82 generally have lower $T_{\mathrm{gs}}$, higher $\Delta H_{\mathrm{ms}}$ and $\Delta H_{\mathrm{mcs}}$, and smaller supercooling necessary for crystallization on cooling $\left(T_{\mathrm{ms}}-T_{\mathrm{mcs}}\right)$. These results show that in these two polymers the dissolution of polyamide segment into PCL domain is relatively smaller and the crystallization of PCL segment is relatively easier than other PCL-polyamide block copolymers, ${ }^{10.11,15}$ because of higher molecular weight or lower content of polyamide segment. Whereas, 2P1CN73 generally has higher $T_{\mathrm{gs}}$, lower $\Delta H_{\mathrm{ms}}$ and $\Delta H_{\mathrm{mcs}}$, and larger value of $T_{\mathrm{ms}}-T_{\mathrm{mcs}}$ than other block copolymers. These results show that the dissolution of polyamide segment into PCL domain, i.e., phase mixing is enhanced when the molecular weight of PCL segment is small. ${ }^{10,11,15}$ In our previous papers, ${ }^{6,7}$ we compared the properties of PCL diol/ MDI/BD based TPE nonionomers with those of PCL diol/MDI/BD/dimethylol propionic acid (DMPA) based TPE ionomers. And we observed lower residual strain
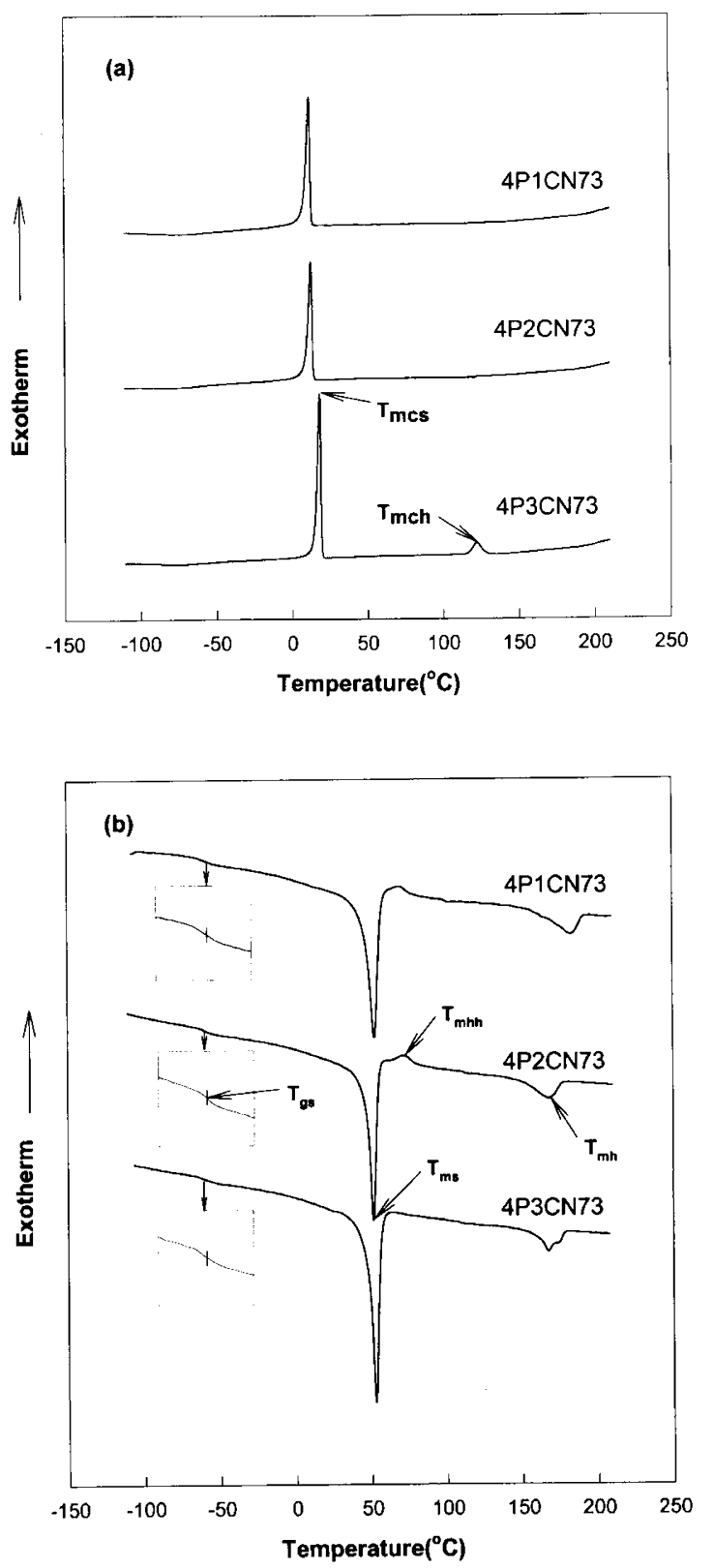

Figure 2. DSC thermograms obtained (a) on cooling and (b) on heating.

after shape recovery with TPE ionomers due to the enhanced microphase separation between soft and hard segments and due to higher rubbery plateau modulus. When the molecular weight and the content of PCL 
H. Y. LEE et al.

Table III. Thermal properties of PCL-polyamide block copolymer

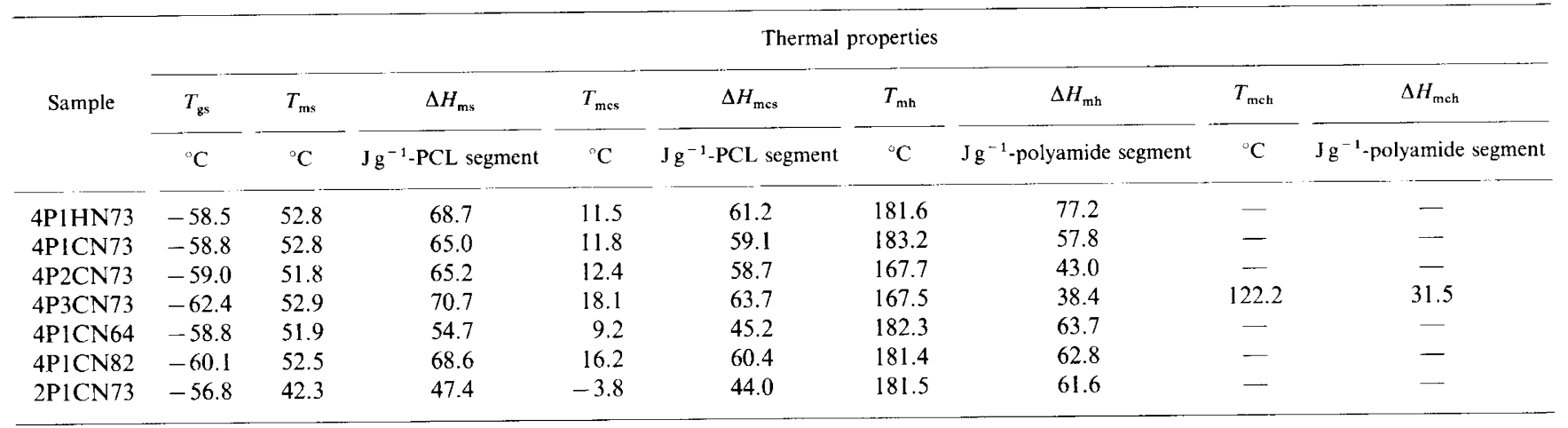

segment was 4000 and $70 \mathrm{wt} \%, \Delta H_{\mathrm{ms}}$ of TPE ionomer and TPE nonionomer were $64 \mathrm{~J} \mathrm{~g}^{-1}$-PCL segment and $57 \mathrm{~J} \mathrm{~g}^{-1}$-PCL segment, and somewhat higher value of $\Delta H_{\mathrm{ms}}$ in TPE ionomer compared with nonionomer was explained to be due to enhanced microphase separation. In Table III, we can see that $\Delta H_{\mathrm{ms}}$ is higher than $64 \mathrm{~J} \mathrm{~g}^{-1}$-PCL segment when the molecular weight and the content of PCL segment is 4000 and $70 \mathrm{wt} \%$, and this suggests that the microphase separation is enhanced as $\mathrm{MDI} / \mathrm{BD}$ based polyurethane hard segment is replaced by polyamide segment. About $\Delta H_{\mathrm{mh}}$, we can see in Table III that HPA1 segment with intrinsic regular chemical structure has the highest value. The broad or multiple endothermic melting peaks of copolyamide blocks (Figure 2) and copolyamide oligoners (not shown in this paper) show the presence of heterogeneity in the copolyamide crystal region, probably due to copolymeric chemical structures.

\section{Dynamic Mechanical Properties}

The change of tensile storage modulus, $E^{\prime}$ in PCL-polyamide block copolymers and 4TPE73 on heating are shown in Figure 3. Gradual decrease of $E^{\prime}$ at the temperature range between $T_{\mathrm{gs}}$ and $T_{\mathrm{ms}}$, and a sudden drop of $E^{\prime}$ at $T_{\mathrm{ms}}$ can be observed. The rubbery plateau above $T_{\mathrm{ms}}$ of PCL-polyamide block copolymer extends upto $160-190^{\circ} \mathrm{C}$, and the abnormal slight increase of $E^{\prime}$ above $90^{\circ} \mathrm{C}$ in $4 \mathrm{P} 1 \mathrm{CN} 73$ and $2 \mathrm{P} 1 \mathrm{CN} 73$ seems to be due to the additional crystallization of polyamide segment which was not crystallized during the casting at $90^{\circ} \mathrm{C}$.

The tensile storage moduli $\left(E^{\prime}\right)$ of $4 \mathrm{P} 1 \mathrm{CN} 73$ have larger values than those of 4TPE73. It can also be observed in Figure 3 that the $E^{\prime}$ values at rubbery plateaus of PCL-polyamide block copolymer do not decrease so much on heating upto $T_{\mathrm{mb}}$, compared with TPEs in our previous paper. ${ }^{6,7}$ These high rubbery moduli suggest that these PCL-polyamide block copolymers will have high elastic recovery at high temperature, because the driving force of shape recovery is the elastic force generated during the deformation, when the deformation is less than the yield value.

When compared with 4P1CN73, 2P1CN73 has smaller $E^{\prime}$ value below $T_{\mathrm{ms}}$ and larger rubbery plateau modulus. This smaller $E^{\prime}$ value below $T_{\mathrm{ms}}$ and earlier crystal-rubber transition might be due to lower crystallinity and larger $T_{\mathrm{ms}}$ depression(Table III) of PCL phase respectively, caused by enhanced PCL-polyamide phase mixing at lower molecular weight of PCL segment. The higher

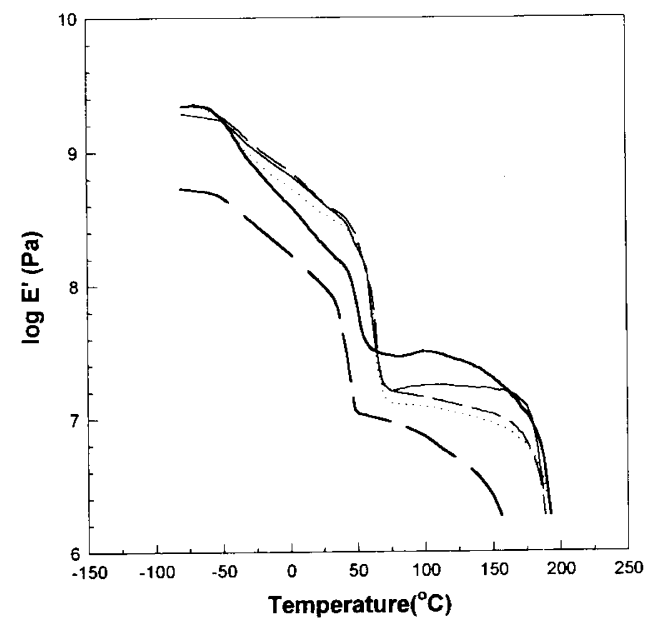

Figure 3. Dynamic mechanical properties of $(-) 4 \mathrm{PICN} 73,(---)$ 4P3CN73, (--.-) 4P1CN82, (-) 2PICN73, and (- - ) 4TPE73.

rubbery plateau modulus of $2 \mathrm{P} 1 \mathrm{CN} 73$ suggests that well distributed polyamide segment can do its role as a fixed phase in the rubbery PCL phase more effectively. Similar result was also observed in PCL-poly(butylene terephthalate) (PBT) multiblock copolymer. ${ }^{3}$ That is, lower modulus below $T_{\mathrm{ms}}$ and larger rubbery modulus above $T_{\mathrm{ms}}$ were observed when the phase mixing was enhanced by the reduced molecular weight of PCL and PBT blocks. And those results were explained by the reduced crystallization of PCL phase and finer distribution of PBT segment in rubbery PCL phase, respectively.

The 4P3CN73 and the 4P1CN73 have similar values of $E^{\prime}$ below $T_{\mathrm{ms}}$, however, 4P1CN73 has somewhat higher value of rubbery plateau modulus than that of $4 \mathrm{P} 3 \mathrm{CN} 73$. This also supports that finer distribution of polyamide segment at low molecular weight is positive for its role as a fixed phase at rubbery state.

In Figure 3, both tensile storage moduli below and above $T_{\mathrm{ms}}$ of $4 \mathrm{P} 1 \mathrm{CN} 82$ are smaller when compared with 4P1CN73, as expected from smaller amount of polyamide segment which acts as a fixed phase. However, in our previous papers, the tensile moduli of both TPE ionomer and nonionomer were increased as the weight ratio of PCL soft segment/polyurethane hard segment was increased due to the predominant contribution by crystalline PCL phase on $E^{\prime}$ below $T_{\text {ms }}$, compared with the contribution by higher amount of hard segment having more rigid structure. These results show that the contribution of polyamide segment on $E^{\prime}$ is larger than 
Table IV. Tensile properties of PCL-polyamide block copolymers

\begin{tabular}{lccc}
\hline & $\begin{array}{c}\text { 3\% secant } \\
\text { modulus }\end{array}$ & $\begin{array}{c}\text { Tensile } \\
\text { strength }\end{array}$ & $\begin{array}{c}\text { Elongation } \\
\text { at break }\end{array}$ \\
\cline { 2 - 3 } & $\mathrm{MPa}$ & $\mathrm{MPa}$ & $\%$ \\
4P1HN73 & 156 & 51 & 620 \\
4P1CN73 & 124 & 71 & 890 \\
4P3CH73 & 138 & 55 & 970 \\
4P1CN64 & 178 & 51 & 880 \\
4P1CN82 & 126 & 51 & 820 \\
2P1CN73 & 101 & 55 & 1040 \\
\hline
\end{tabular}

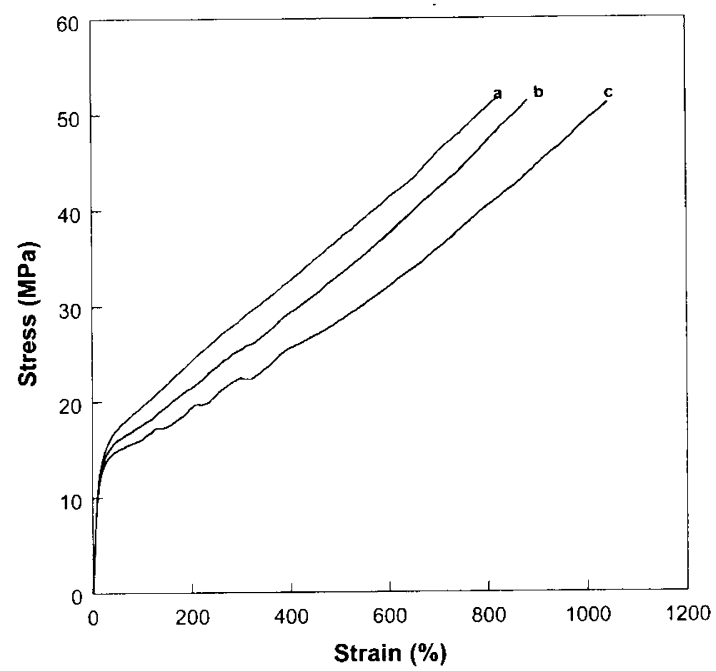

Figure 4. Stress- strain curves of (a) 4P1CN64, (b) 4P1CN73, and (c) 4 PICN82 at room temperature.

that of polyurethane hard segment.

The earlier crystal-rubber transition of 4TPE73 compared with 4P1CN73 and 4P3CN73, shows the larger $T_{\mathrm{ms}}$ depression of PCL phase due to larger phase mixing in 4TPE73.

\section{Tensile Properties}

The tensile properties measured at room temperature are summarized in Table IV, and three typical stressstrain curves are shown in Figure 4. The properties are similar with those of TPEs in our previous papers, ${ }^{6,7}$ when the molecular weight and the content of PCL segment are the same. The $3 \%$ secant modulus generally increases as the molecular weight and the content of polyamide segment are increased.

\section{Shape Memory Behavior}

Typical results of cyclic tensile test to examine the shape memory effect of PCL-polyamide block copolymers and 4TPE73 are shown in Figure $5 .^{6,7,16,17}$ Sample was elongated at $65^{\circ} \mathrm{C}$ to $100 \%$ strain $\left(\varepsilon_{\mathrm{m}}\right)$ at a constant elongation rate of $500 \mathrm{~mm} \mathrm{~min}^{-1}$. While maintaining the strain at $\varepsilon_{\mathrm{m}}$, sample was cooled to $25^{\circ} \mathrm{C}$ and unloaded. Upon removing the constraint at $25^{\circ} \mathrm{C}$, small recovery of strain to $\varepsilon_{\mathbf{u}}$ occurs. The sample was subsequently heated to $65^{\circ} \mathrm{C}$ in $5 \mathrm{~min}$, and stayed at that temperature for the next $10 \mathrm{~min}$, allowing recovery of strain. This completes on thermomechanical cycle $(N=1)$ leaving a
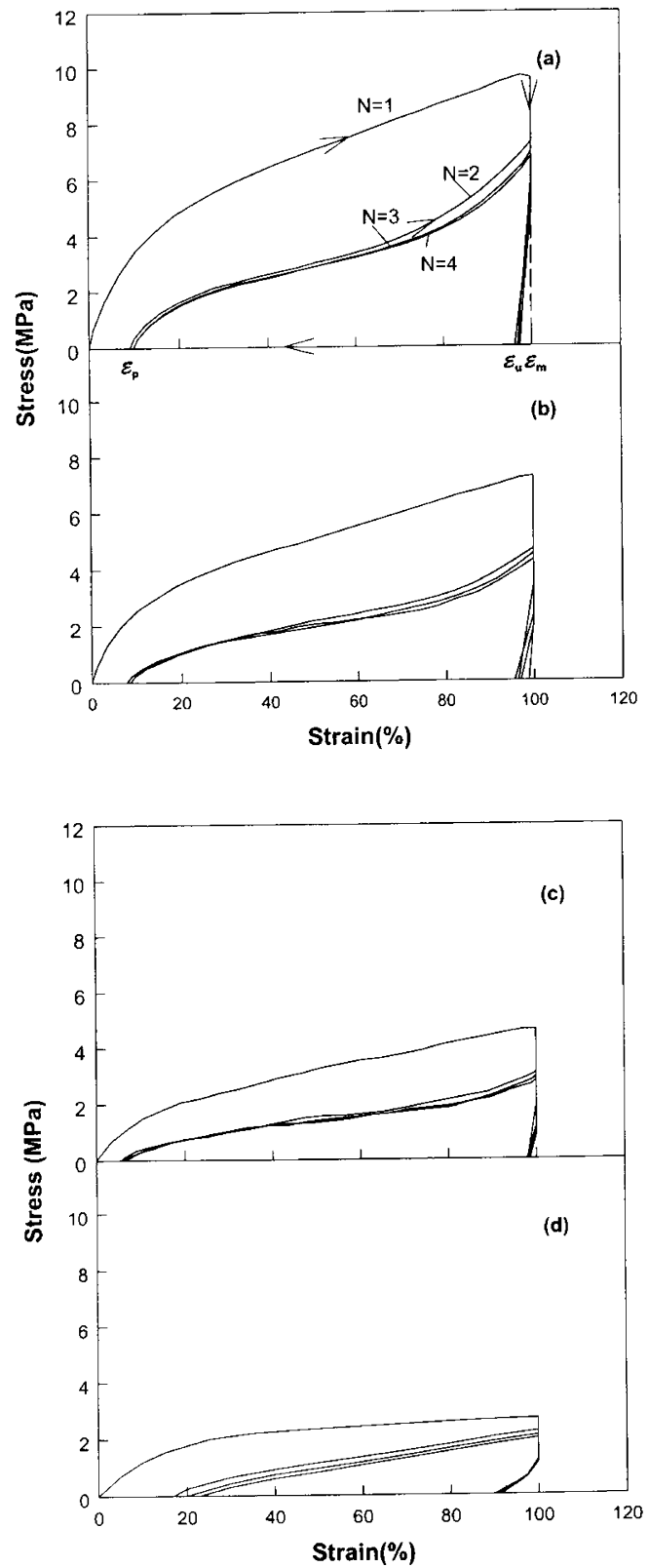

Figure 5. Cyclic tensile behavior of (a) $4 \mathrm{P} 1 \mathrm{CN} 64$, (b) $4 \mathrm{P} 1 \mathrm{CN} 73$, (c) 4 P1CN82, and (d) 4TPE73.

Table V. Residual strain after thermomechanical cycle of PCL-polyamide block copolymers and 4TPE73

\begin{tabular}{|c|c|c|c|}
\hline & & $\varepsilon_{p} / \%$ after & \\
\hline & $N=1$ & $N=2$ & $N=3$ \\
\hline 4P1HN73 & 7.3 & 8.4 & 8.5 \\
\hline $4 \mathrm{P} 1 \mathrm{CN} 73$ & 7.8 & 8.6 & 8.6 \\
\hline $4 \mathrm{P} 2 \mathrm{CN} 73$ & 8.1 & 9.2 & 10.6 \\
\hline $4 \mathrm{P} 3 \mathrm{CN} 73$ & 9.4 & 11.1 & 11.4 \\
\hline 4P1CN64 & 9.1 & 10.0 & 9.9 \\
\hline $4 \mathrm{PICN} 82$ & 5.6 & 6.4 & 6.3 \\
\hline $2 \mathrm{PlCN} 73$ & 6.5 & 7.1 & 7.3 \\
\hline 4TPE73 & 17.0 & 20.0 & 23.0 \\
\hline
\end{tabular}

residual strain $\varepsilon_{\mathrm{p}}$, where the next cycle $(N=2)$ starts.

In Figure 5, we can see that cyclic tensile test curves of PCL-polyamide block copolymers maintain their shapes almost identically after first tempering cycle. And Table $\mathrm{V}$ shows that $\varepsilon_{\mathrm{p}}$ values does not vary so much 
upon repeated thermomechanical cycle and their values lies around $10 \%$. When we carried out twenty thermomechanical cycles with $4 \mathrm{P} 1 \mathrm{CN} 73$ and $4 \mathrm{P} 1 \mathrm{CN} 82$, the results were almost the same. These results are somewhat different from those of TPEs, ${ }^{6,7,16,17}$ where the shape of curves were changed and $\varepsilon_{\mathrm{p}}$ increased from about $20 \%$ remarkably by the repeated thermomechanical cycles (one example is Figure 5(d)). Because fatigue by repeated deformations in TPEs comes from soft-hard phase mixing and orientation, ${ }^{18,19}$ these results show that changes in phase mixing or segmental orientation by repeated deformations are not so much in PCL-polyamide block copolymers.

The variation of $\varepsilon_{\mathrm{p}}$ in Table $\mathrm{V}$ according to the kind of PCL-polyamide block copolymer show the following orders: 4P1CN64 $>4 \mathrm{P} 1 \mathrm{CN} 73>4 \mathrm{P} 1 \mathrm{CN} 82$ by the content of PCL block, 4P1CN73 $>2 \mathrm{P} 1 \mathrm{CN} 73$ by the length of PCL block, and 4P3CN73 $>4 \mathrm{P} 2 \mathrm{CN} 73>4 \mathrm{P} 1 \mathrm{CN} 73$ by the length of polyamide block. The reduction of $\varepsilon_{p}$ at higher content of PCL segment was also observed in TPE's ${ }^{2}$, however, the reduction of $\varepsilon_{\mathrm{p}}$ at shorter block length of reversible (PCL) or fixed(polyamide) segment is somewhat different from those of TPE's.

As anticipated from higher rubbery modulus (Figure 3 ), stress necessary for deformation of 4P1CN73 is higher, in Figure 5, than that of 4TPE73.6,7 This suggests that PCL-polyamide block copolymer will have higher recovery stress which is necessary for practical application as shape memory materials.

\section{CONCLUSIONS}

Compared with TPEs, PCL-polyamide block copolymers,

1. showed enhanced microphase separation

2. had higher rubbery plateau modulus which persists stably upto $T_{\mathrm{mh}}$

3. needed higher stress for deformation at $65^{\circ} \mathrm{C}$
4. showed lower degree of fatigue by repeated deformation in shape memory behavior.

Acknowledgment. The authors wish to acknowledge the financial support (Project Number: 997-002-E00445) of the Korea Research Foundation made in the program year of 1997.

\section{REFERENCES}

1. S. Hayashi, Int. Prog. Urethanes, 6, 90 (1993).

2. K. Sugimoto, Plastics Age, June, 165 (1989).

3. Y. J. Choi, B. K. Kim, and H. M. Jcong, Polymer (Korea), 22, 131 (1998).

4. A. Matsuda, J. Sato, H. Yasunaga, and Y. Osada, Macromolecules, 27, 7695 (1994).

5. H.-L. Li, K. Ito, Y. Ujihira, A. Nanasawa, and T. Iwamoto, Kobunshi Ronbunshu, 55, 448 (1998).

6. B. K. Kim, S. Y. Lee, and M. Xu, Polymer, 37, 5781 (1996).

7. B. K. Kim, S. Y. Lee, J. S. Lee, S. H. Baek, Y. J. Choi, J. O. Lee, and M. Xu, Polymer, 39, 2803(1998).

8. C. B. Wang and S. L. Cooper, Macromolecules, 16, 775 (1983).

9. S. Abouzahr and G. L. Wilkes, J. Appl. Polym. Sci., 29, 2695 (1984).

10. T. O. Ahn, I. S. Choi, S. W. Lee, and H. M. Jeong, Macromol. Chem. Phys., 195, 2559 (1994).

11. T. O. Ahn, M.-H. Oh, K. S. Yoo, and H. M. Jeong, Polym. Int., 36, 239 (1995).

12. N. S. Schneider and C. S. Paik Sung, Polym. Eng. Sci., 17, 73 (1977).

13. J. W. C. Van Bogart, P. E. Gibson, and S. L. Cooper, J. Polym. Sci., Polym. Phys., 21, 65 (1983).

14. C. G. Seefried, Jr., J. V. Koleske, and F. E. Critchfield, J. Appl. Polym. Sci., 19, 2493 (1975).

15. T. O. Ahn, I. S. Choi, H. M. Jeong, and K. Cho, Polym. Int., 31, 329 (1993).

16. H. Tobushi, S. Hayashi, and S. Kojima, Nippon Kikai Gakkai Ronbunshu, A57, 2760 (1991).

17. H. Tobushi, S. Hayashi, and S. Kojima, JSME Intern. J., 35, 296 (1992).

18. M. Shibayama, T. Kawauchi, T. Kotani, S. Nomura, and T. Matsuda, Polym. J., 18, 719 (1986).

19. W. Tang, W. J. MacKnight, and S. L. Hsu, Macromolecules, 28, 4284 (1995). 